\title{
A Modified Asynchronous Transfer Mode Fuzzy Policer
}

\begin{abstract}
M.R.M. Rizk, H. Rashwan and A. Abdel Aziz
Department of Electrical Engineering, Faculty of Engineering, Alexandria University, Alexandria, Egypt.

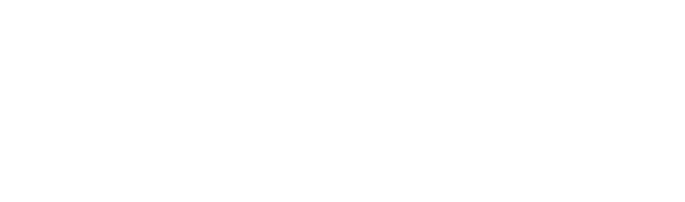

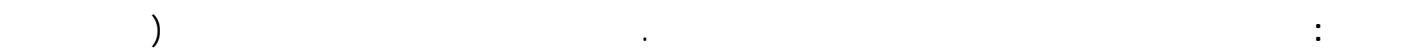

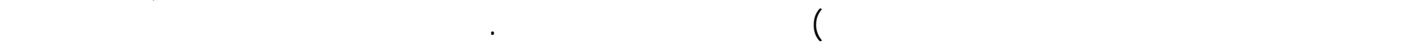

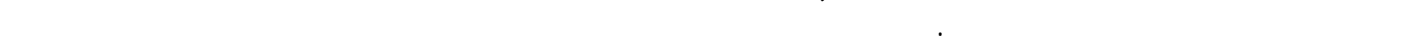

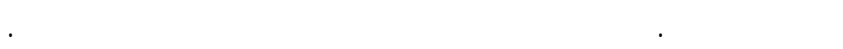

ABSTRACT: A Modified Fuzzy policer for Asynchronous Transfer Mode is introduced. In a preceding fuzzy policer model the time window (time interval where ATM cells are accepted in the policer) is not synchronized with the source activity. In the proposed one, the time windows are not consecutive but are triggered by the first arriving cell. The modified policer gives good improvement to the selectivity, and minimizes the congestion over the path. This improvement can be significant for multiple channels.
\end{abstract}

KEYWORDS: Fuzzy Logic, Asynchronous Transfer Mode, Usage Parameter Control.

\section{Introduction}

$\mathbf{T}$ he basic characteristics of Asynchronous Transfer Mode (ATM) networks (De Prycker, 1993) are the provision of broadband user access interfaces, packet-oriented information transfer without flow control between the user and the network, and the use of statistical multiplexing. Due to these properties, a call can, in principle, exceed the negotiated traffic parameters up to the maximum capacity of the User Network Interface (UNI) (Rathgeb, 1991).

One of the advantages of ATM compared to other networking technologies is the support of various service qualities (De Prycker, 1993). ATM layer traffic control is designed to avoid network congestion by preventative traffic management. Network congestion is a state when the network cannot meet the negotiated network performance objectives for established connections or for new connection requests. The goal of traffic control is to protect the network, and other users of the network, so that everyone receives the performance that they pay for and depend on (HewlettPakard, 1995). In order to achieve a guaranteed service quality QoS, the user has to commit to a specific traffic contract during connection setup. The service provider should guarantee the parameters of this traffic contract. They will be one of the main factors a potential customer will be charged for. On the other hand, the service provider needs to control if the customer's cell stream entering the network really behaves compliant to the negotiated traffic contract. If not, the network equipment has to take appropriate measures to protect the network from intentionally or accidentally misbehaving users. These so called policing functions are well defined in the ATM and B-ISDN specifications under the category "Usage Parameter Control" ( UPC) (Catania et al., 1996). 
This paper presents a new fuzzy policer mechanism. A full study and evaluation of the existing fuzzy policer mechanism published in (Catania et al., 1996) is performed. Then a proposed modification to this fuzzy mechanism is introduced and implemented. In section one we describe the traffic source that was used in the comparison and the evaluation of the mechanisms. In section two we simulate the existing fuzzy policer mechanism, described in (Catania et al., 1996) and compare the results with the published one. In section three we propose a modification to this fuzzy mechanism, which improve the performance of the policer. In section four a comparison between the Leaky bucket mechanism, the existing fuzzy policer mechanism, and the modified fuzzy policer mechanism was done through a software simulation for the three mechanisms. In the last section we concluded our results and recommended some points for further study.

\section{Traffic Source Model}

The two-phase burst/silence model shown in Figure 1 has been used for the comparison of the various mechanisms. This model has been used in earlier publications (Rathgeb, 1991). It allows the relevant parameters, namely maximum cell rate, mean cell rate, and mean burst duration to be varied independently of each other. The number of cells per burst is assumed to have a geometric distribution with mean $\mathrm{E}[\mathrm{X}]$; the duration of the silence phases is assumed to be distributed according to an exponential distribution with mean $\mathrm{E}[\mathrm{S}]$, and the cell interarrival time during a burst is given by $t_{c}$

With

$$
\alpha^{-1}=E[X] \times t_{c}
$$

and

$$
\beta^{-1}=\mathrm{E}[\mathrm{S}]
$$

The mean cell rate $\lambda$ is defined as

$$
\lambda=\frac{1}{t_{c}+\frac{\alpha t_{c}}{\beta}}
$$

\section{Study of the Fuzzy Policer Mechanism (Catania et al., 1996)}

A software simulator using MATLAB (MATLAB, 1997) was implemented and used to validate the results for the fuzzy policer mechanism (Catania et al., 1996). The Figure of merit considered is the selectivity of the mechanisms. We used the source described in the above section with the same statistical parameters as in (Catania et al., 1996) in order to compare the results. Therefore we assumed a voice source with a peak bit-rate $32 \mathrm{~Kb} / \mathrm{s}$, cell inter-arrival time $t_{\mathrm{c}}$ of 12 $\mathrm{ms}, \mathrm{E}[\mathrm{X}]=29$ cells (mean burst duration $350 \mathrm{~ms}$ ), and $\mathrm{E}[\mathrm{S}]=650 \mathrm{~ms}$. From equations (1), (2), and (3), taking into consideration the ATM cell size is 53 bytes, the negotiated mean cell rate $\lambda_{\mathrm{n}}=$ 29 cells/s.

The membership functions for the fuzzy sets are shown in Figure 2, where $A_{o i}, A_{i}, N_{i}$, and $\Delta \mathrm{N}_{\mathrm{i}+1}$ are defined as follows: $\mathrm{A}_{\mathrm{oi}}$ the average number of cell arrivals per window since the start of the connection, $A_{i}$ the number of cell arrivals in the ith window, the threshold $\mathrm{N}_{\mathrm{i}}$ in the ith window indicating the current degree of tolerance the mechanism has over the source, and $\Delta \mathrm{N}_{\mathrm{i}+1}$ represents the variation to be made to the threshold $\mathrm{N}_{\mathrm{i}}$ in the $\mathrm{i}+1$ window (Figure 3 ). $\mathrm{N}$ is equal to the expected value of cells per window $\left(\mathrm{N}=\mathrm{T} \lambda_{\mathrm{n}}\right)$, MAX equals the maximum number of cells that can arrive in a window $\left(\mathrm{T} / \mathrm{t}_{\mathrm{c}}\right)$, where $\mathrm{t}_{\mathrm{c}}$ is the cell inter-arrival time during a burst, $\mathrm{N}_{\mathrm{i} \text {-max }}=9 \mathrm{~N}$ indicates the upper bound value for the $\mathrm{N}_{\mathrm{i}}$ variable, and $\mathrm{N}_{1}=3.5 \mathrm{~N}$ which is the value to be attributed to $\mathrm{N}_{\mathrm{i}}$ at the beginning of the connection. 


\section{A MODIFIED ASYNCHRONOUS TRANSFER MODE FUZZY POLICER}

$\mathrm{N}_{1}=300$.

Choosing $\mathrm{T}=3$ seconds in the simulation gives, $\mathrm{N}=87$ cells, $\mathrm{MAX}=250$ cells, $\mathrm{N}_{\mathrm{i}-\max }=783$,

If $\mathrm{P}_{\mathrm{d}}$ represents the probability that the policer mechanism detects a cell excessive, the ideal behavior would be that $P_{d}$ is zero with the mean cell rate up to the nominal one, and $P_{d}=(\sigma-1) / \sigma$ for $\sigma>1$ for $\sigma>1$, where $\sigma$ is the long-term actual mean cell rate of the source normalized to the negotiated mean cell rate.

In order to obtain the curve $P_{d}$ versus $\sigma$, we assume that a variation in the cell rate is due to a change in the average number of cells per burst $\mathrm{E}(\mathrm{X})$, while the average silence time is assumed to be constant $(E(S)=650 \mathrm{~ms})$. Also, in order to evaluate the capabilities of the mechanisms to react to different kinds of violations, we made the mean cell rate vary by decreasing the average silence time $E(S)$, and keeping the number of cells per burst constant $(E(X)=29$ cells). The chosen generated traffic source duration is about 3 minutes, which is enough for $\mathrm{P}_{\mathrm{d}}$ to go to the steady state.

The following table1.gives the results of the simulation compared to the existing results.

Table 1: Comparison between simulation results and existing results for the fuzzy policer mechanism.

\begin{tabular}{|l|l|l|l|l|l|}
\hline$\sigma$ & $\begin{array}{l}\text { Existing } \\
\text { fuzzy } \\
\text { policer. } \\
{\left[\begin{array}{c}\mathrm{E}(\mathrm{X}) \text { const. } \\
\mathrm{P}_{\mathrm{d}}\end{array}\right.}\end{array}$ & $\begin{array}{l}\text { Simulated. } \\
\text { fuzzy policer. } \\
{[\mathrm{E}(\mathrm{X}) \text { const. }]}\end{array}$ & $\begin{array}{l}\text { Existing } \\
\text { fuzzy pol. } \\
{[\mathrm{E}(\mathrm{S}) \text { const }]}\end{array}$ & $\begin{array}{l}\text { Simulated. } \\
\text { fuzzy pol. } \\
{[\mathrm{E}(\mathrm{S}) \text { const. }]}\end{array}$ & $\begin{array}{l}\text { Ideal Behavior } \\
(\sigma-1) / \sigma \text { for } \\
\sigma>1\end{array}$ \\
\hline 0.95 & 0 & 0 & 0 & $\mathrm{P}_{\mathrm{d}}$ & $\mathrm{P}_{\mathrm{d}}$ \\
\hline 1.0 & $<10^{-8}$ & $<10^{-6}$ & $<10^{-8}$ & $<10^{-6}$ & 0 \\
\hline 1.05 & 0.031090 & 0.022 & 0.033753 & 0.02 & 0.04762 \\
\hline 1.1 & 0.078306 & 0.066 & 0.087029 & 0.087 & 0.09091 \\
\hline 1.2 & 0.135768 & 0.13 & 0.155668 & 0.154 & 0.16667 \\
\hline 1.3 & 0.18623 & 0.185 & 0.211353 & 0.206 & 0.2307 \\
\hline 1.4 & 0.248756 & 0.239 & 0.278909 & 0.26 & 0.2857 \\
\hline 1.5 & 0.283214 & 0.278 & 0.310451 & 0.31 & 0.3333 \\
\hline 1.6 & 0.327301 & 0.321 & 0.342940 & 0.338 & 0.375 \\
\hline 1.7 & 0.372404 & 0.372 & 0.378184 & 0.375 & 0.4117 \\
\hline 1.8 & 0.418008 & 0.41 & 0.411373 & 0.407 & 0.44444 \\
\hline 1.9 & 0.457541 & 0.445 & 0.444393 & 0.435 & 0.47368 \\
\hline 2.0 & 0.492144 & 0.4855 & 0.476444 & 0.47 & 0.50 \\
\hline & & & & & \\
\hline
\end{tabular}


M.R.M. RIZK, H. RASHWAN and A. ABDEL AZIZ

Geometric

Exponential

Mean $\mathrm{E}[\mathrm{X}] \mathrm{t}_{\mathrm{c}}$ Mean E [S]
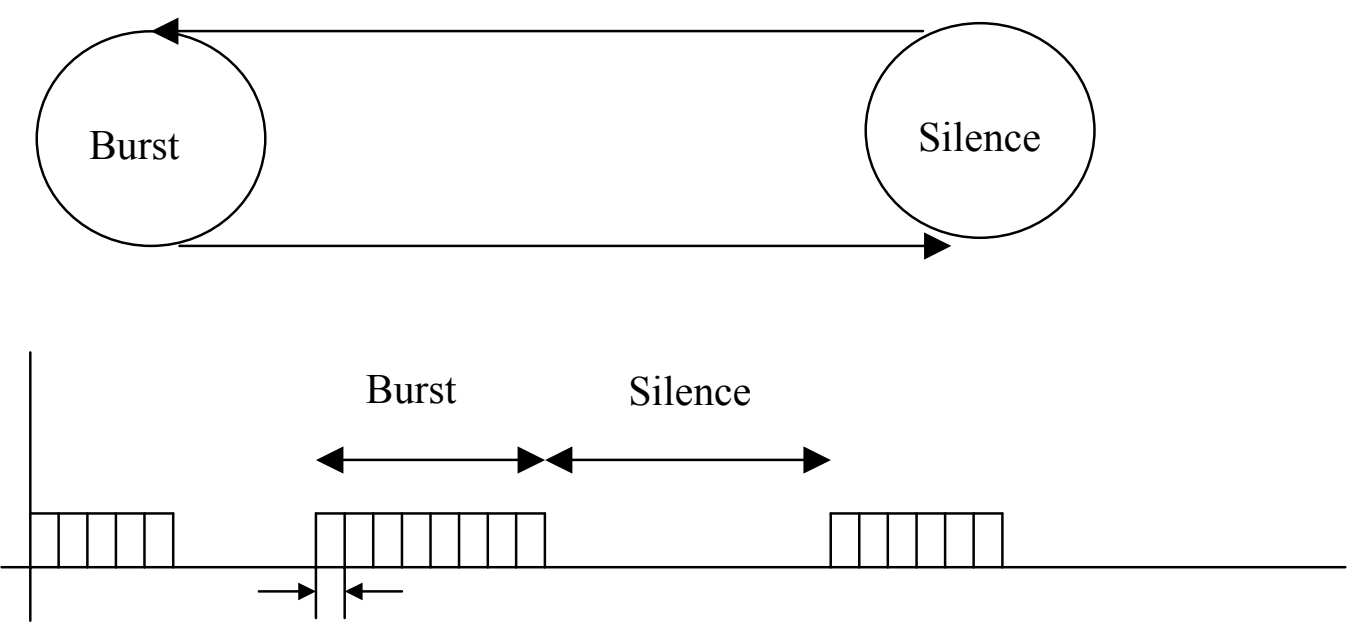

$t_{c}$

Figure 1. Two-phase burst/silence source model.

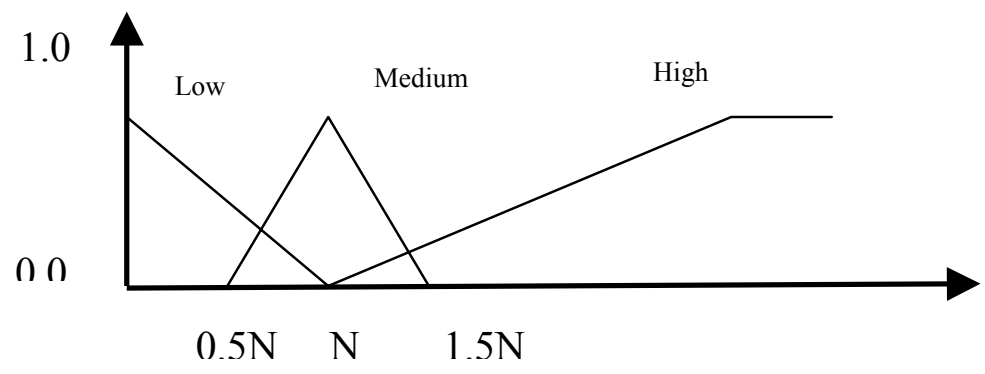

Membership functions for the $\mathrm{A}_{0 \mathrm{i}}$ and $\mathrm{A}_{\mathrm{i}}$ input

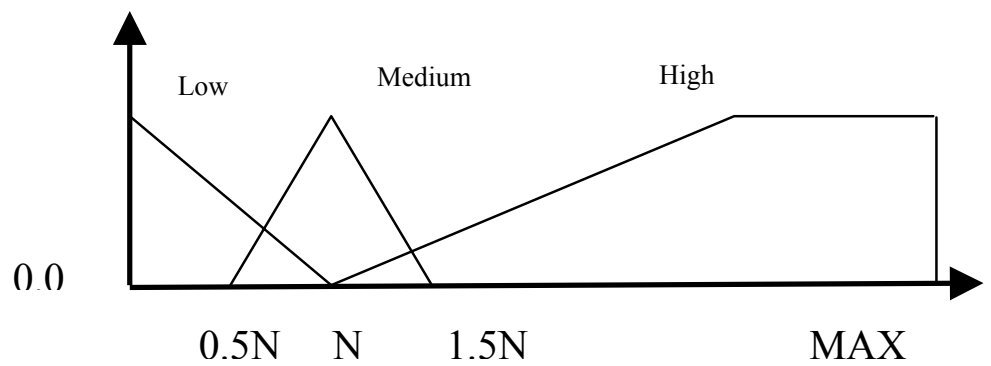

Membership functions for the $\mathrm{N}_{\mathrm{i}}$ input variable

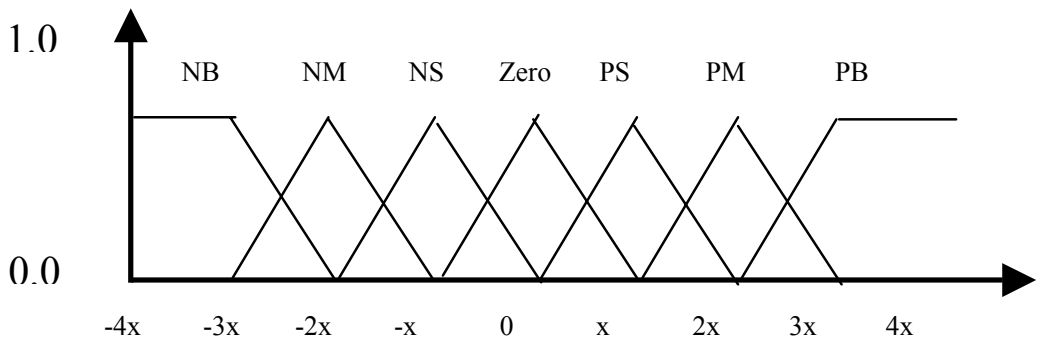

Membership functions for the $\Delta \mathrm{N}_{\mathrm{i}+1}$ output variable

Figure 2: Membership functions for the existing fuzzy policer mechanism. 


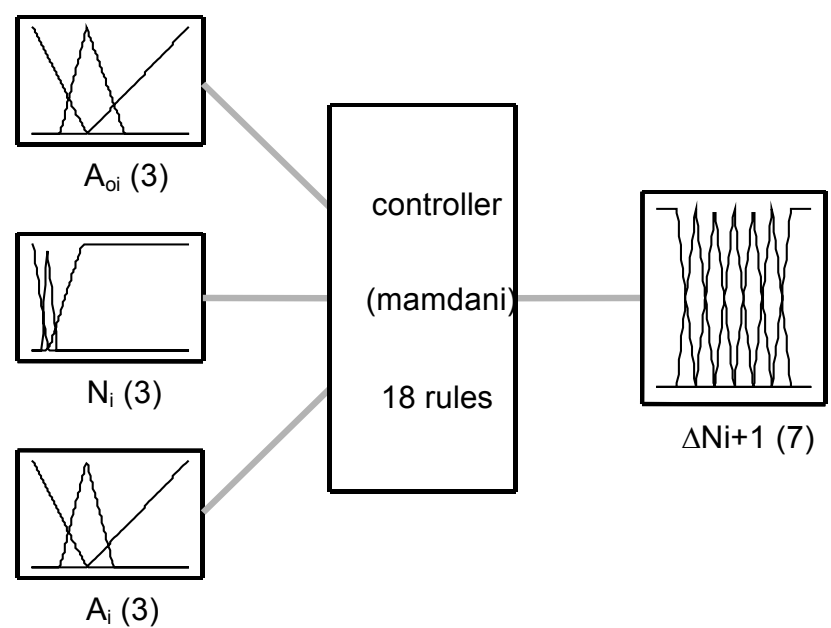

Figure 3. System controller: 3 inputs, 1 output.

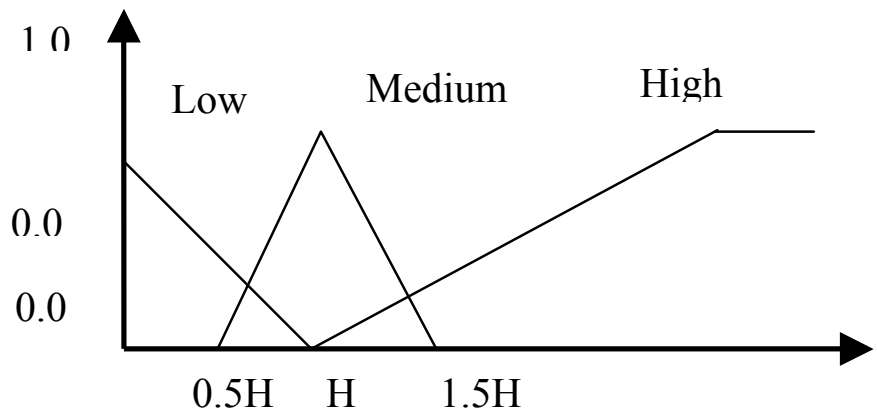

Membership functions for the $\mathrm{A}_{0 \mathrm{i}}$ and $\mathrm{A}_{\mathrm{i}}$ input variables

1.0

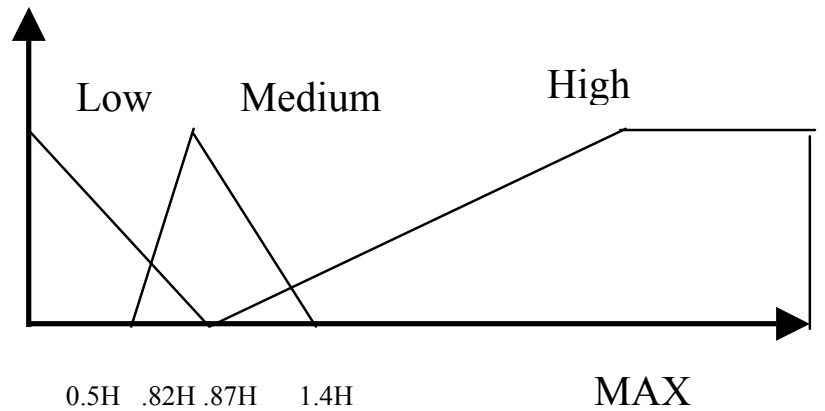

Membership functions for the $\mathrm{N}_{\mathrm{i}}$ input variable

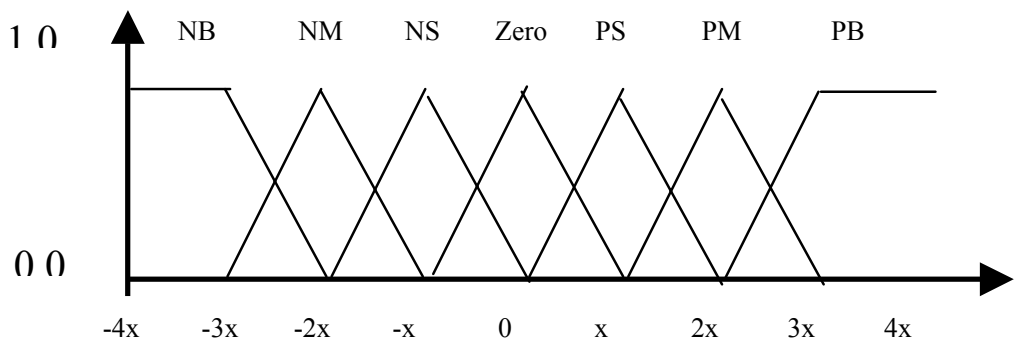

Membership functions for the $\Delta \mathrm{N}_{\mathrm{i}+1}$ output variable $(\mathrm{x}=\mathrm{H} / 22)$

Figure 4. Membership functions for the modified fuzzy policer mechanism. 
It is clear from the above table that the simulation results almost coincide with the published ones for the same traffic source model. This validates the simulated mechanism and the existing results. Since our simulation is justified so we can compare these results with the results from other policer such as the one proposed in the next section.

\section{Modified Fuzzy Policer Model}

In the preceding fuzzy policer model the time window is not synchronized with the source activity. In the proposed fuzzy policer mechanism the time windows are not consecutive but are triggered by the first arriving cell.

Table 2: The simulation results for $\mathrm{E}(\mathrm{s})$ constant.

\begin{tabular}{|c|c|c|c|c|}
\hline$\sigma$ & $\begin{array}{c}\text { Leaky Bucket } \\
\mathrm{C}=1.42 \\
{[\mathrm{E}(\mathrm{S}) \text { constant }]} \\
\mathrm{P}_{\mathrm{d}}\end{array}$ & $\begin{array}{c}\text { Existing fuzzy } \\
\text { policer } \\
\text { [E(S) constant }] \\
\mathrm{P}_{\mathrm{d}}\end{array}$ & $\begin{array}{c}\text { Modified fuzzy } \\
\text { policer } \\
{[\mathrm{E}(\mathrm{S}) \text { constant }]} \\
\mathrm{P}_{\mathrm{d}}\end{array}$ & $\begin{array}{l}\text { Ideal behavior } \\
\qquad \begin{array}{c}\sigma-1) / \sigma \\
\text { for } \sigma>1 \\
P_{d}\end{array}\end{array}$ \\
\hline 0.95 & 0 & 0 & 0 & 0 \\
\hline 1.0 & 0 & $<10^{-6}$ & $<10^{-6}$ & 0 \\
\hline 1.05 & 0 & 0.02 & 0.03 & 0.04762 \\
\hline 1.1 & 0 & 0.087 & 0.085 & 0.0909 \\
\hline 1.2 & 0 & 0.154 & 0.155 & 0.166666 \\
\hline 1.3 & 0 & 0.206 & 0.212 & 0.2307 \\
\hline 1.4 & 0.01 & 0.26 & 0.265 & 0.2857 \\
\hline 1.5 & 0.045 & 0.31 & 0.325 & 0.3333 \\
\hline 1.6 & 0.1 & 0.338 & 0.369 & 0.375 \\
\hline 1.7 & 0.1552 & 0.375 & 0.408 & 0.4117 \\
\hline 1.8 & 0.2017 & 0.407 & 0.435 & 0.44444 \\
\hline 1.9 & 0.2472 & 0.435 & 0.469 & 0.47368 \\
\hline 2.0 & 0.28 & 0.47 & 0.495 & 0.50 \\
\hline
\end{tabular}

We used the same input and output for the fuzzy controller. The membership functions chosen for the fuzzy sets of this modified controller was obtained through trial and error until it reached a level of performance considered to be adequate as shown in Figure 5.4. $H$ represents the average number of cells arrival per trigger window for an ideal source, MAX is the maximum number of cells that can arrive in a window $\left(T / t_{c}\right), N_{i-\max }$ is equal to $9 H$, and the value for the beginning of the connection is $H_{1}=3.5 \mathrm{H}$. 


\section{A MODIFIED ASYNCHRONOUS TRANSFER MODE FUZZY POLICER}

\section{Performance Evaluation}

In this section, we compare the performance of the three mechanisms [Leaky Bucket, existing fuzzy policer, and the modified fuzzy policer]. The Figure of merit considered is the selectivity of the mechanisms. To assess the performance of the three mechanisms a simulator is implemented using MATLAB to generate the traffic source and evaluate the three mechanisms. The traffic source model used here is the same as the one used in section 3, whose statistical parameters are those typical to a real packetized source. Considering a peak bit-rate of $32 \mathrm{~Kb} / \mathrm{s}$ and a cell interarrival time $t_{c}$ of $12 \mathrm{~ms}$ the traffic parameters are typically $\mathrm{E}[\mathrm{X}]=29$ cells (mean burst duration $350 \mathrm{~ms}$ ) and $\mathrm{E}[\mathrm{S}]=650 \mathrm{~ms}$.

It is worth pointing out that for this kind of source, traditional policing methods proved to be inefficient. To achieve a low false alarm probability, it is necessary to have either a high value for the counter limit, $\mathrm{N}$, which means a poor dynamic response, or a high value for the over dimensioning factor $\mathrm{C}>2$, which reduces the capability to detect a violation.

For the Leaky Bucket $\mathrm{N}=45, \mathrm{C}=1.42$ where $\mathrm{N}$ is the counter limit and $\mathrm{C}$ is a over dimensioning factor (Catania et al., 1996).

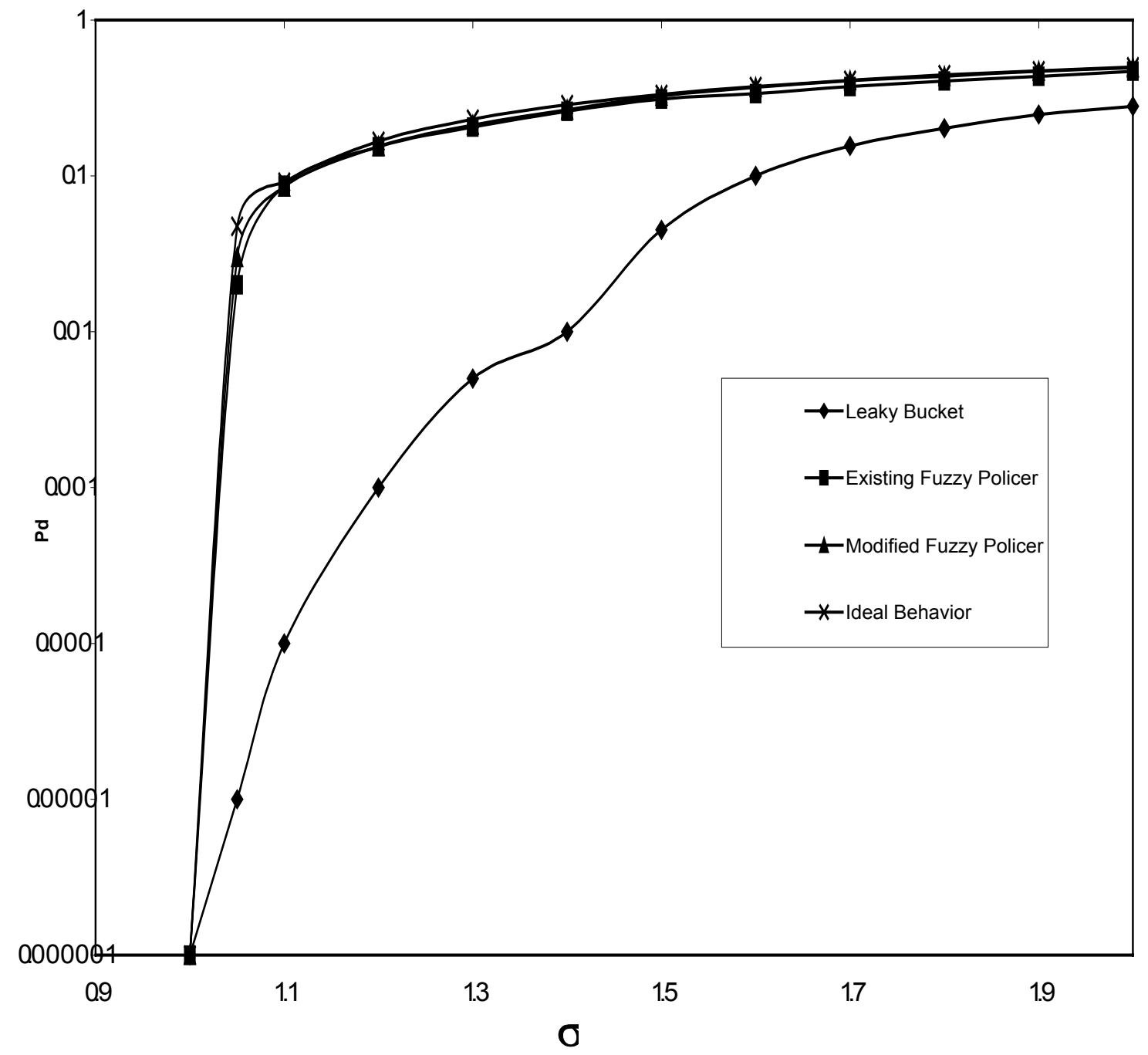

Figure 5. Selectivity for a packetized voice source E(S) constant. 
For the fuzzy policer mechanism we choose a window size $\mathrm{T}=3 \mathrm{~s}$ (about three burst/silence) so $\mathrm{N}=87$ cells and $\mathrm{N}_{1}=300$ (Catania et al., 1996).

For the modified policer mechanism a window size of $\mathrm{T}=4 \mathrm{~s}$ (about four burst/silence) showed a better performance compared to the existing mechanism, this gives $\mathrm{H}=129$ cells and $\mathrm{H}_{1}=400$.

Table 3: The simulation results for $\mathrm{E}(\mathrm{X})$ constant.

\begin{tabular}{|c|c|c|c|c|}
\hline$\sigma$ & $\begin{array}{l}\text { Leaky Bucket } \\
\qquad \begin{array}{c}\mathrm{C}=1.42 \\
\mathrm{E}(\mathrm{x}) \text { constant } \\
\mathrm{P}_{\mathrm{d}}\end{array}\end{array}$ & $\begin{array}{c}\text { Existing fuzzy } \\
\text { policer } \\
{[\mathrm{E}(\mathrm{x}) \text { constant }]} \\
\mathrm{P}_{\mathrm{d}}\end{array}$ & $\begin{array}{c}\text { Modified fuzzy } \\
\text { policer } \\
{[\mathrm{E}(\mathrm{x}) \text { constant }]} \\
\mathrm{P}_{\mathrm{d}}\end{array}$ & $\begin{array}{c}\text { Ideal } \\
\text { behavior } \\
(\sigma-1) / \sigma \\
\text { for }>1 \\
\mathrm{P}_{\mathrm{d}}\end{array}$ \\
\hline 0.95 & 0 & 0 & 0 & 0 \\
\hline 1.0 & 0 & $<10^{-6}$ & $<10^{-6}$ & 0 \\
\hline 1.05 & 0 & 0.022 & 0.015 & 0.04762 \\
\hline 1.1 & 0 & 0.066 & 0.055 & 0.0909 \\
\hline 1.2 & 0 & 0.13 & 0.12 & 0.166666 \\
\hline 1.3 & 0 & 0.185 & 0.182 & 0.2307 \\
\hline 1.4 & 0.005 & 0.239 & 0.221 & 0.2857 \\
\hline 1.5 & 0.037 & 0.278 & 0.2783 & 0.3333 \\
\hline 1.6 & 0.095 & 0.321 & 0.333 & 0.375 \\
\hline 1.7 & 0.155 & 0.372 & 0.392 & 0.4117 \\
\hline 1.8 & 0.18 & 0.41 & 0.426 & 0.44444 \\
\hline 1.9 & 0.245 & 0.445 & 0.46 & 0.47368 \\
\hline 2.0 & 0.3 & 0.4855 & 0.4995 & 0.50 \\
\hline
\end{tabular}

As discussed in section 3 , in order to obtain the curve $P_{d}$ versus $\sigma$, we assume that a variation in the cell rate is due to a change in the average number of cells per burst $E(X)$, while the average silence $\mathrm{E}(\mathrm{S})=650 \mathrm{~ms}$ time is assumed to be constant. It is shown from Figure 5, which compares the selectivity performance versus cell rate variation for the three mechanism, that the modified fuzzy Policer and the existing fuzzy Policer give an improvement for $\mathrm{P}_{\mathrm{d}}$ compared to the Leaky Bucket in table 2.

From the numerical values we can conclude that the modified fuzzy mechanism give an improvement to $P_{d}$ for $\sigma$ greater than 1.5 as compared to the existing fuzzy mechanism.

In order to evaluate the capabilities of the mechanisms to react to different kinds of violations, we made the mean cell rate vary by decreasing the average silence time $\mathrm{E}(\mathrm{S})$, and keeping the number of cells per burst constant $(\mathrm{E}(\mathrm{X})=29$ cells).

As expected, the modified fuzzy policer and the existing fuzzy policer give an improvement for $P_{d}$ compared to the leaky bucket mechanism (Figure 6). From table 3, the modified fuzzy policer gives an improvement to $\mathrm{P}_{\mathrm{d}}$ for $\sigma$ greater than 1.5 as compared to the Fuzzy Mechanism. 


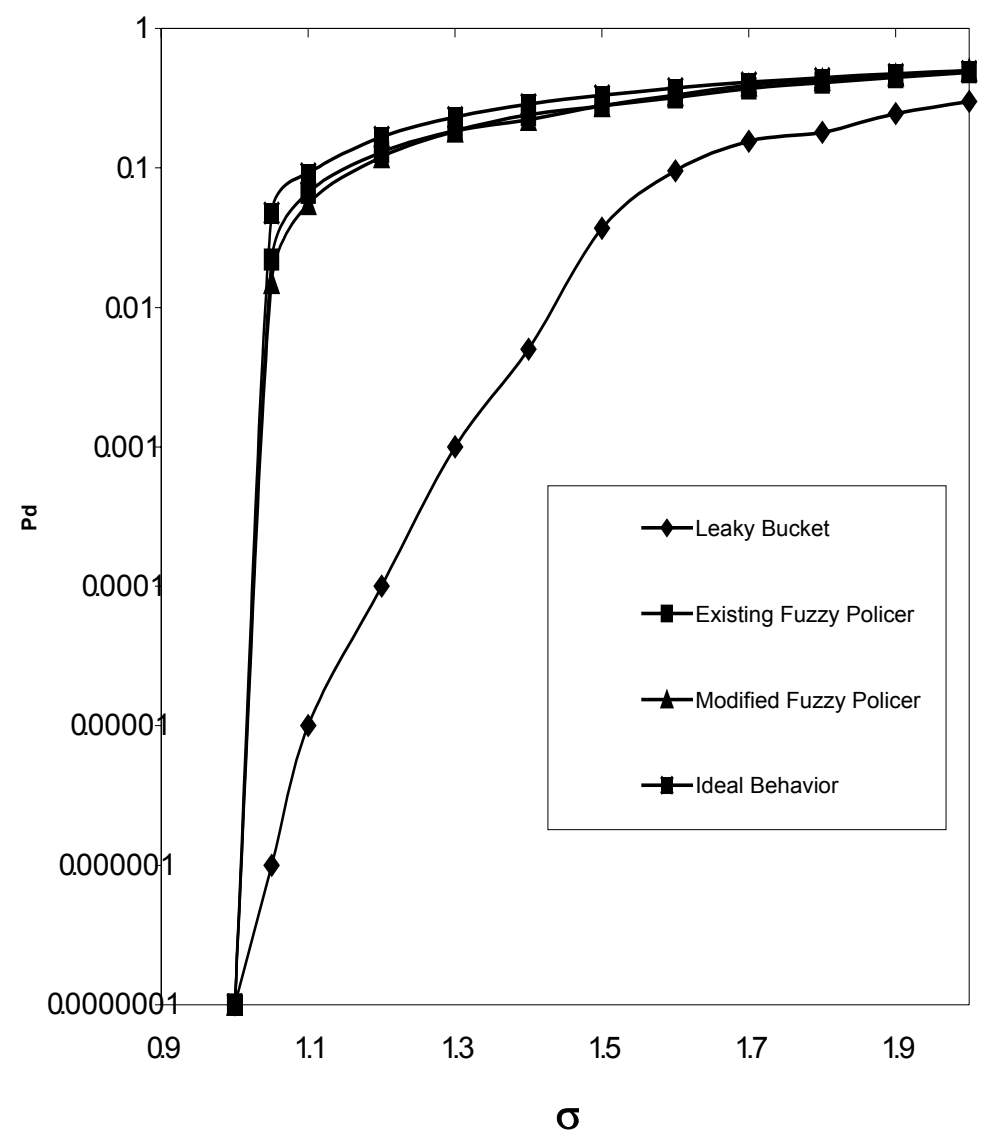

Figure 6. Selectivity performance for a packetized voice source $\mathrm{E}(\mathrm{X})$ constant.

\section{Conclusions}

We can conclude from the given results that in general the intelligent mechanisms give a good improvement to the selectivity over traditional mechanisms, and the proposed modifications to the existing fuzzy policer give an improvement to the selectivity for value of $\sigma$ greater than 1.5 which in turn minimize the congestion over the path. This improvement can be significant for multiple channels.

Also, an important conclusion is that the number of windows processed by the modified fuzzy policer mechanism is reduced by a factor of $2 / 3$ compared to the existing fuzzy policer mechanism for the same source and the same duration of the connection. This in turn leads to a reduction in the processor time.

We recommend the following points for further study. First optimization of the membership function for a given traffic model. Second using the modified fuzzy policer mechanism to test different traffic sources, such as video on demand, and adjust the needed variations in the membership functions.

\section{References}

CATANIA, V., FICILI, G., PALAZZO, S. and PANNO, D. 1996. A Comparative Analysis of Fuzzy Versus Conventional Policing Mechanisms for ATM Networks," IEEE/ACM Trans. Networking, 4(3): 449-459. 
DE PRYCKER, M. 1993. Asynchrounus Transfer Mode: Solution for Broadband ISDN,(2nd Edition) Ellis-Horwood.

HEWLETT-PAKARD. 1995. Test \& Measurement Application Notes "Traffic Policing" 5963$7510 \mathrm{E}$.

MATLAB. 1997. The Language of Technical Computing, The MathWorks, Inc., version 5.1.0.421.

RATHGEB, E.P. 1991. Modeling and Performance Comparison of Policing Mechanisms for ATM Networks. IEEE journal Selected Areas in Communications. 9(3): 325-334.

Received 26 June 2001

Accepted 25 February 2002 